\title{
RECURSOS TECNOLÓGICOS E ENSINO DE LÍNGUA MATERNA E ESTRANGEIRA (A DISTÂNCIA OU SEMIPRESENCIAL)
}

\author{
Angelita Gouveia Quevedo* \\ Mercedes Fátima de Canha Crescitelli*
}

\begin{abstract}
Resumo: Depois de uma breve visão histórica da educação a distância, promovemos uma reflexão acerca do uso de recursos tecnológicos no ensino (a distância, semipresencial ${ }^{3}$ ou presencial) de línguas materna e estrangeira e mostramos por que razão consideramos as tecnologias digitais, em especial o computador, ferramentas importantes para o desenvolvimento dos processos de aprendizagem.
\end{abstract}

Palavras-chave: educação a distância (EAD), aprendizagem de língua, Internet, recursos tecnológicos digitais.

\section{Considerações iniciais}

As Diretrizes dos Cursos de Letras (CNE, 2001) e as Diretrizes de Formação de Professores (CNE, 2002) evidenciaram a urgência de os cursos de graduação voltarem seu olhar para o uso de recursos tecnológicos no ensino e para iniciativas de ensino semipresencial e a distância. Consideramos, portanto, que a expectativa é que os pesquisadores contribuam para que os alunos, especialmente os futuros professores, sejam preparados para esse contexto educacional contemporâneo. Não é por outra razão que o Grupo de Pesquisa de Tecnologia Educacional e Educação a Distância (TEED) da Faculdade de Comunicação e Filosofia da PUC-SP tem reunido esforços para a implantação da modalidade semipresencial de ensino nos cursos de graduação em Letras, com base em toda experiência já reunida em cursos de extensão a distância (ministrados via COGEAE) de língua portuguesa e de línguas estrangeiras e ainda nas pesquisas que vêm sendo desenvolvidas sobre Educação a Distância (EAD) há pelo menos dez anos pelos professores dessa Faculdade.

São muitas as questões fundamentais para a implementação adequada de cursos a distância, seja em nível de extensão, seja em nível de graduação por meio da oferta de disciplinas semipresenciais, de língua portuguesa e de língua estrangeira, como complemento ao ensino presencial em cursos de graduação, em nosso caso, com enfoque especial para o curso de Letras. Neste artigo, objetivamos discutir sobre o uso de recursos tecnológicos no ensino de línguas, tendo por base nossa experiência em cursos de extensão totalmente a distância e em disciplinas semipresenciais ou presenciais em cursos de graduação e algumas pesquisas desenvolvidas pelo grupo TEED. O texto está organizado em três partes: na primeira, abordamos brevemente o histórico da EAD para, em seguida, tratar das gerações dessa modalidade de ensino e,

\footnotetext{
* Mestranda do Programa de Pós-Graduação em Língua Portuguesa da Pontifícia Universidade Católica de São Paulo

* Professora do Programa de Pós-Graduação em Língua Portuguesa da Pontifícia Universidade Católica de São Paulo

${ }^{3}$ Ensino semipresencial: modalidade híbrida que contempla encontros presenciais, além das aulas a distância.
} 
por fim, considerar a importância dos recursos tecnológicos para os processos de aprendizagem.

\section{Breve histórico de EAD}

Quando, na atualidade, referimo-nos a Tecnologias de Informação e Comunicação (TICs) ou a Educação a Distância (EAD) logo nos vem à lembrança a imagem de computadores potentes e velozes pelos quais transitam gigabites de informações - um mundo de conhecimento que aguarda para ser descoberto e conquistado com apenas um clique. Evidentemente, nem sempre foi assim. A EAD possui uma longa história. Alguns estudiosos do assunto, entre os quais Romiszowski (2004) e Almeida (s/d.), consideram que essa modalidade de ensino data das epístolas de São Paulo e aparece como uma atividade comercial no século 19 com os propagados cursos de correspondência para treinamento vocacional e educação continuada.

É preciso dizer que a EAD realmente surgiu em meio a um processo desenvolvimentista no qual a escola era compreendida como espaço de qualificação de mão-de-obra para as demandas econômicas que também viam a utilização de tecnologia educacional como propícia para o atendimento daquelas necessidades. Esse cenário contribuiu para que, equivocadamente, a EAD fosse associada com a educação tecnicista, em que apenas métodos e técnicas interessam (MORAES, 1997). Na verdade, a EAD começou a desfrutar de mais respeito apenas a partir da segunda metade do século 20 com o sucesso da Open University (Universidade Aberta) da Inglaterra.

No Brasil, os registros sobre a criação de EAD são imprecisos. Afirma-se que ela teve início com os cursos por correspondência no começo do século $20^{4}$ e que se configurava como alternativa para fazer a educação convencional chegar às pessoas residentes em áreas longínquas e isoladas ou àqueles que não reuniam condições de cursar o ensino regular. Também aqui a EAD era vista de modo depreciativo, de maneira que a pouca importância atribuída a ela e as dificuldades dos correios na época contribuíram para o ensino por correspondência receber pouco incentivo das autoridades.

Um dos marcos da EAD no Brasil foi a utilização do rádio para fins educativos na década de 20 por Roquete Pinto no Projeto Minerva, que transmitia programas de literatura, línguas e de outros interesses comunitários (FONTANA, s/d.). O rádio educativo surgiu em 1923 com a fundação da Rádio Sociedade do Rio de Janeiro, por um grupo liderado por Henrique Morize e Roquete Pinto. A emissora foi doada ao Ministério da Educação e Saúde em 1936 e, no ano seguinte, foi criado o Serviço de Radiofusão Educativa do Ministério da Educação (ALVES, s/d.).

Depois, houve as iniciativas do Instituto Universal Brasileiro, em 1941, e do Senac, em 1946, com a Universidade do Ar que, em 1950, já atingia 318 localidades. Na década seguinte, criou-se o Movimento de Educação de Base (MEB), que objetivava alfabetizar jovens e adultos utilizando escolas radiofônicas inicialmente nas regiões Norte, Nordeste e Centro-Oeste, e mais tarde, em 1965, também na Região Sul, por meio da Fundação Educacional e Cultural Padre Landell de Moura. Em 1967, a Fundação Padre Anchieta transmitiu o programa como uma promoção educativa e cultural, via rádio e TV para o estado de São Paulo.

No entanto, somente a partir do final da década de 60 do século passado, a EAD realmente começou a ter expressão no Brasil. De 60 a 80, novas entidades foram criadas para o desenvolvimento da educação por correspondência. Na década de 70 , com a

\footnotetext{
${ }^{4}$ Entretanto, em 1891, o Jornal do Brasil registrou na primeira edição da seção de classificados, anúncio oferecendo profissionalização para datilógrafos por correspondência (ALVES, s/d).
} 
criação do Programa Nacional de Teleducação (PRONTEL) surgiu a Televisão Educativa (TVE), que possibilitou o lançamento de muitos projetos educativos voltados primordialmente para a educação pública ${ }^{5}$, os quais possuíam a finalidade de oferecer uma segunda oportunidade para adultos e adolescentes completarem seus estudos de primeiro e segundo graus (ROMISZOWSKI, 2004).

Nessa fase em que a prática dominante de EAD no Brasil se circunscrevia aos telecursos divulgados pelos meios de massa (rádio/TV), alguns projetos fizeram uso da recepção organizada, por meio da qual os alunos se reuniam em grupos acompanhados de um monitor, orientador ou facilitador para assistir às teleaulas e desenvolver as atividades de aprendizagem. Outros usaram a recepção livre que implicava estudo individual em casa. Uma das críticas recebidas pelos projetos de telecurso dizia respeito à insuficiência do atendimento sistemático aos alunos (ALONSO, s/d.).

É fundamental, porém, que se diga que esse foi um momento significativo para a EAD no Brasil porque contribuiu para ajudar a paulatinamente ir mudando sua imagem: os melhores projetos brasileiros ganharam o reconhecimento internacional - o telecurso de segundo grau, da TVE do Maranhão; os telecursos supletivos para adultos, da TVE Amazonas; o telecurso do Instituto de Radiofusão do Estado da Bahia e o Projeto SACI.

Em fins dos anos 70, um levantamento feito com apoio do Ministério da Educação apontava para a existência de 31 estabelecimentos de ensino que usavam a metodologia de ensino a distância, distribuídos entre os estados de São Paulo e Rio de Janeiro. A partir de 1985, as mudanças em EAD passam a ocorrer de forma muito rápida: com o progressivo desenvolvimento das TICs, dá-se início à chamada geração digital, a terceira geração de EAD.

\section{Gerações de EAD}

Podemos identificar a existência ao menos de três gerações de EAD, segundo Moore \& Kearsley (1996). No entanto, conforme mostraram Sherron \& Boettcher (1997), haveria ainda uma quarta geração e até mesmo uma quinta. De qualquer modo, é fundamental não perder de vista, antes de passarmos ao detalhamento dessas gerações, que elas sinalizam o surgimento de diferentes tecnologias para produção, distribuição e comunicação, mas que isso não significa, por exemplo, que a primeira geração tenha sido suplantada pela segunda e que não exista mais.

A Primeira Geração de EAD compreende o período que vai até 1970 e tem sido denominada também geração textual por ser caracterizada pelo estudo por correspondência quando os materiais impressos eram enviados pelo correio.

A Segunda Geração de EAD, de 1970 a 1985, é conhecida também como geração analógica. Nessa época, surgem as primeiras universidades abertas que, além do material impresso, fazem uso de transmissões por televisão aberta, rádio, fitas de áudio e de vídeo, com interação por telefone, satélite e TV a cabo.

Já a Terceira Geração tem lugar no período que vai de 1985 até 1995. Denominada, também, de geração digital, ela representa a EAD que surge como resultado do uso de redes de conferência por computador e estações de trabalho multimídia.

A Quarta Geração, por sua vez, segundo Sherron \& Boettcher (1997), compreende o período que se inicia em 1995 e vem até os dias de hoje, sendo caracterizada pelo crescente uso de tecnologias de banda larga que permitem, entre outras coisas, que o aluno participe de experiências de vídeo interativo (ao vivo).

\footnotetext{
${ }^{5}$ Entre eles, estavam o Projeto Minerva, o Projeto SACI, o Telecurso de $1^{\circ}$ e $2^{\circ}$ Graus e o Mobral.
} 
Como já afirmamos, há ainda os estudiosos que tratam de uma Quinta Geração que seria uma derivação da anterior e que, além de incluir a comunicação via computadores, com sistema de respostas automatizadas, e bancos de dados de objetos inteligentes com potencial para oferecer experiências de aprendizagem personalizadas, possibilita acesso via portal ao campus universitário virtual (Taylor, 2001).

Importa registrar que a geração digital de EAD ajuda a fazer com que essa modalidade educacional deixe de ser um ensino de "segunda categoria" para ter o mesmo nível e potencial de qualidade da educação presencial. A propagação dos computadores pessoais e o advento da Internet são marcos da passagem da segunda para a terceira geração. Nessa última, há o surgimento de ferramentas de comunicação que vão promover interação síncrona (chat, vídeo e teleconferência) e assíncrona (e-mail, fóruns, listas de discussão, blogs) entre os participantes de uma comunidade virtual. Vislumbra-se, dessa maneira, um novo cenário para a EAD, a despeito dos preconceitos de que ainda é alvo. Na mesma direção, no fim da década de 80 e início dos anos 90 do século passado, surgem iniciativas pioneiras e muito importantes para alterar o curso da história de EAD no Brasil. Trata-se de ações governamentais como o programa Salto para o Futuro, TVEscola, PROINFO e Proformação, entre outros, assim como de ações da Universidade de Brasília, da Universidade Federal do Mato Grosso e da UFSC (ROMISZOWSKI, 2004).

\section{Ensino de línguas a distância e uso de recursos tecnológicos}

O ponto de partida para a discussão que aqui será empreendida é a maneira como concebemos a tecnologia e o computador: trata-se de produtos socioculturais que, por meio da ação humana, têm condições de atuar como ferramenta física e simbólica para compreendermos o mundo (LIÓN, 1995; LANTOLF, 2000).

Desde sempre, uma das características básicas da educação a distância foi o estabelecimento de uma comunicação de dupla via. Professor e aluno não estão juntos no mesmo espaço físico da sala de aula presencial e precisam, desse modo, de meios que possibilitem a comunicação, os quais podem ser: correspondência postal, telefone, telex, fax, rádio e televisão apoiada em meios abertos de dupla comunicação, correspondência eletrônica etc. Consideramos, no entanto, que, em virtude das tecnologias informáticas conversacionais da atualidade, agora sim pode-se afirmar com propriedade que a comunicação entre professor e aluno e entre aluno e aluno é real, possível e plenamente viabilizada. Para nós, esse é um dos aspectos mais revelantes nesse cenário: entramos na era da comunicação interativa, muito mais promissora para a modalidade educacional a distância do que a comunicação massiva da época em que havia apenas rádio e TV.

Estamos, portanto, no contexto da geração digital de EAD. Nele, a Internet configura-se como o meio em que ocorrem novos formatos de interação ainda pouco estudados. Como a educação a distância vem sendo consolidada, mais recentemente, por meio dos inúmeros cursos ministrados via rede, o que era então visto como uma forma especial de ensino, que usava um sistema não tradicional, está se tornando um fator importante na educação também porque agora possibilita de fato o diálogo e a interação mais imediatos entre os participantes. Desse modo, vemos que a EAD ganha respeito como modalidade educacional de relevo.

O cenário mais favorável na atualidade para a essa modalidade de educação decorre ainda do fato de que as tecnologias são vistas como ferramentas importantes para o 
desenvolvimento de processos construtivos de aprendizagem, para a criação de novos espaços de aprendizagem, de novas formas de representação da realidade, para ampliação de contextos e maior incentivo aos processos cooperativos de produção do conhecimento (MORAES, 2002: 02).

Com a evolução tecnológica e o crescimento das aplicações das tecnologias digitais na educação, as pesquisas que se desenvolvem em universidades brasileiras vêm sinalizando que tais tecnologias podem também favorecer o desenvolvimento do pensamento reflexivo (VALENTE, 1999) e da consciência crítica, além de viabilizar o encontro de soluções para os novos problemas que surgem, entre os quais podemos citar: o acesso democrático às informações e, conseqüentemente, o acúmulo de conteúdos, sem a sua devida seleção; o (re)posicionamento da educação diante do avanço das TICs no desenvolvimento humano; o uso de toda a potencialidade das tecnologias a fim de formar indivíduos para uma nova cidadania etc.

Considerando esse potencial que as tecnologias podem ter como incentivadoras de processos cooperativos e colaborativos de produção de conhecimento a que se refere Moraes (2002), o uso adequado das ferramentas computacionais e também de ambientes virtuais de aprendizagem que favorecem construir o conhecimento de forma compartilhada viabiliza o desenvolvimento de processos reflexivos sobre o próprio processo de aprender e de construir sentidos, por meio de atividades de exploração, investigação e descoberta realizadas individualmente ou em grupo, as quais ocorrerão pelo uso da linguagem verbal.

Um fator muito importante para o crescente desenvolvimento das novas tecnologias é o potencial que elas têm para o incentivo da aprendizagem auto-dirigida ${ }^{6}$. $\mathrm{O}$ aprendiz auto-dirigido é visto como um indivíduo que adquire novos conhecimentos por intermédio do diálogo com o professor, do feedback que dele recebe e por meio da reflexão que é levado a fazer em parceria com os professores, os facilitadores, os monitores ou os colegas de aprendizagem. Essa comunicação com os outros, que ocorre primordialmente pelo uso da escrita no caso da interação em cursos a distância ou semipresenciais, permite que o aprendiz acesse outras perspectivas que o levem a conhecer mais profundamente as temáticas envolvidas no curso e a própria língua que é objeto de sua aprendizagem.

Evidentemente, o computador por si só não provoca as mudanças desejadas e nem viabiliza a construção de conhecimentos. O ensino de língua com o uso de recursos tecnológicos depende de que o professor saiba efetivamente usar as ferramentas de modo adequado nos ambientes de aprendizagem de maneira a estimular o trabalho colaborativo, a levar o aluno a compartilhar os saberes individuais, a formular e solucionar questões e a buscar informações contextualizadas às dinâmicas sociais de aprendizagem.

O próprio uso da Internet tem de ser levado em conta sempre pelo professor online que precisa oferecer condições adequadas para o aluno, já que ela constitui um excelente recurso de aprendizagem, por meio do qual se tem acesso não só a bibliotecas, artigos, publicações online, referências bibliográficas, listas de discussão, como também a outros ambientes virtuais de aprendizagem. Mais do que isso, especialmente para o ensino de língua, a Internet é uma porta de entrada às inúmeras possibilidades de usos lingüísticos, que variam de acordo com os gêneros textuais digitais. Muitos pesquisadores têm se voltado para o estudo das diferentes práticas sociais em curso na

\footnotetext{
${ }^{6}$ A aprendizagem auto-dirigida descreve o processo no qual os indivíduos tomam a iniciativa de, com ou sem a ajuda de outros, diagnosticar as suas necessidades de aprendizagem, formular objetivos de aprendizagem, identificar os recursos humanos e materiais para aprender, escolher e implementar as estratégias apropriadas, e avaliar os resultados na aprendizagem (KNOWLES, 1975).
} 
rede e levar o aluno a percebê-las para se posicionar de forma crítica diante delas é também uma empreitada a ser realizada por aqueles que ensinam língua em cursos a distância ou semipresenciais.

No caso da aprendizagem de língua estrangeira, o acesso a ambientes internacionais online de comunicação, a diversidade de informações sobre os mais variados assuntos e domínios de conhecimento, o acesso a material autêntico nos mais diversos formatos e etc. auxiliam no processo contínuo de apropriação lingüística.

Nos últimos anos, um número significativo de estudos têm sido realizados por pesquisadores brasileiros sobre o uso de recursos eletrônicos especialmente no ensino e na aprendizagem por meio da Internet (MORAN, 1998) e sobre a articulação entre educação, tecnologia e formação de professores para ambientes eletrônicos (ALMEIDA, 2003). Para o ensino e aprendizagem de línguas, em especial, as últimas duas décadas trouxeram uma ampliação expressiva de recursos tecnológicos audiovisuais. Nenhum outro recurso, no entanto, provocou um impacto maior do que o computador pessoal: hoje, além da possibilidade de interação com textos e gráficos gerados por ele, há também uma combinação possível entre sons e imagens analógicas e digitais.

Ocorre, porém, que, para a maioria dos usuários da Internet, o uso que se faz dela e do computador ainda é bastante restrito: no contexto educacional virtual contemporâneo, a linguagem verbal utilizada é, pode-se dizer, a mais importante, porque ainda não é viável utilizarmos todos os recursos multimidiáticos disponíveis já que sua ampla disseminação envolve altos custos. Esse contexto se, por um lado, restringe as possibilidades técnicas, por outro lado, favorece o ensino da modalidade escrita de língua, exigindo do aluno mais contato com a leitura e com a produção de textos escritos.

No trato específico do ensino e aprendizagem de línguas mediado por computador, muitos estudos com temas diversificados têm sido publicados no Brasil, dos quais citamos os seguintes:

- uso de recursos eletrônicos em sala de aula, especialmente por meio da Internet (COLLINS \& BRAGA, 2001);

- gêneros digitais no ensino online de língua (MOTTA-ROTH, 2001; SABBAG, 2002; CRESCITELLI, 2004; ALMEIDA, 2005);

- interação e tecnologia educacional em cursos online de língua (CRESCITELLI \& GERALDINI, 2004);

- diferentes possibilidades de interação que os recursos eletrônicos oferecem e como ela ocorre no ensino de língua no contexto digital (COSTA, 2001; PAIVA, 2001);

- papel do professor de língua em cursos online (FAUSTINI, 2001; GERALDINI, 2003);

- formação de professores para o contexto digital (RAMOS \& FREIRE, 2001; FREIRE, 2003; TAVARES, 2001);

- prática da língua inglesa em ambientes eletrônicos (FREIRE, 2003);

- questões de avaliação de design de cursos de língua online (WAADT, 2002; FREIRE et al., 2004);

- didática para o ensino online de língua (LEFFA, 2003);

- engajamento do aluno em curso online de língua (QUEVEDO, 2005);

- escrita do material didático online no ensino de língua (CRESCITELLI \& CAMPOS, no prelo). 
Ao considerar a aprendizagem de línguas mediada pelo computador, é imprescindível que vejamos a linguagem como um instrumento de mediação por meio do qual o indivíduo interage e se desenvolve dentro do contexto sócio-histórico em que está inserido e a aprendizagem humana como uma experiência social em que a interação se dá pela linguagem e pela ação (VYGOTSKY, 1985).

Desse modo, considera-se que a linguagem (oral e escrita) realiza duas funções cruciais: primeiramente, capacita seus participantes a coordenar suas ações, percepções, crenças e intenções com relação às situações que partilham; em segundo lugar, fornece um meio para representação e reflexão sobre as pessoas, coisas, ações e relações entre elas. A linguagem tem ainda outra função considerando o ponto de vista sociocultural de desenvolvimento: a de fornecer um dos meios principais pelos quais o conhecimento e as práticas construídas no passado são transmitidas para futuras gerações. Entretanto, há muito mais do que a transferência de informações. Pela interação com o contexto, o indivíduo transforma seu potencial para a ação social e também constrói (intramentalmente) o meio para realizar tais ações. É por intermédio da linguagem que o homem faz conexões e cria significados junto com os outros. Ao mesmo tempo, ao experienciar essas conexões, ele aprende e constrói o conhecimento. Nesse sentido, não podemos nos esquecer de que a tecnologia é um produto cultural que atua como mediadora nas relações entre os homens.

A comunicação em tempo real em um espaço virtual corrobora para que o processo educacional se realize cada vez mais sem fronteiras delimitadas. A Internet é a porta de entrada para esse mundo e as TICs podem ser um auxílio muito importante como mediadoras entre teoria e prática. O computador é um instrumento do mundo concreto que faz a mediação entre o aprendiz e o objeto de seu aprendizado e, como elemento cultural, ao ser manejado pelo indivíduo, pode provocar mudanças na sua forma de perceber, simbolizar e atuar sobre o mundo (BORGES, 2000).

$\mathrm{O}$ ensino de línguas a distância ou que utiliza recursos tecnológicos contribui também para que os indivíduos envolvidos possam participar da cultura tecnológica e tenham a oportunidade de desenvolver as necessárias competências e habilidades. Além disso, as demandas contemporâneas impõem que sejamos capazes de participar da sociedade de informação e, para isso, precisamos saber conviver com o seu ritmo constante de mudanças; construir nosso próprio conhecimento e ter a capacidade de refletir, analisar, buscar novas informações, dialogar em um mundo interativo e saber aprender a aprender.

O processo educacional que ocorre por meio do uso de computadores equipados com programas especialmente elaborados para que a tecnologia atue como mediadora do processo de aprendizagem tem muito a contribuir para o ensino de línguas, mas isso apenas não reflete a complexa atividade de aprender com a utilizaçao de recursos tecnológicos. Jonassen (1992: 2) afirma:

(...) as pessoas não aprendem dos computadores, livros, vídeos ou outros recursos que foram desenvolvidos para transmitir informação. A aprendizagem é mediada pelo pensamento (processos mentais). O pensamento é ativado pelas atividades de aprendizagem e as atividades de aprendizagem são mediadas pelas intervenções instrucionais incluindo-se aí as tecnologias. A aprendizagem requer reflexão por parte do aprendiz. Para que mais diretamente afetemos o processo, portanto, devemos nos concentrar menos no design das tecnologias de transmissão e mais no que os aprendizes precisam para completar as diferentes tarefas que lhe são apresentadas. 
O professor por meio de recursos tecnológicos pode estimular práticas que exijam do aluno o raciocínio e que possam resultar no aprender. No entanto, no dizer do autor, os alunos não aprendem simplesmente da tecnologia, mas do pensar sobre o que fazem. O aluno aprende porque reflete sobre o que faz ou fez, sobre aquilo em que acredita, sobre o que outros fizeram, sobre o próprio processo de reflexão. Diferentes práticas engajam diferentes tipos de pensar. Essas práticas podem ser apresentadas pelo professor ou pela tecnologia; entretanto, nem o professor nem a tecnologia causam o pensar, o aprender. A reflexão e a articulação dessa reflexão para a construção do conhecimento são fundamentais para o uso de sistemas de aprendizagem baseados na tecnologia que pretendam realmente contribuir para o desenvolvimento do indivíduo, inclusive no ensino de línguas, porque lhe permite avaliar as decisões que toma, as estratégias que usa e as respostas que encontra.

Para Jonassen et al. (1999), o conhecimento é construído com base na experienciação de fenomênos e na interpretação dessas experiências. Eles argumentam que, para construir o significado, é preciso articular o que foi aprendido, o que pode ser feito de várias formas: pelo incentivo provocado por um problema, uma questão ou um desacordo, que evocam a necessidade ou o desejo de conhecer; pela representação daquilo que é aprendido, ou seja, do significado que é construído; pelo partilhar das experiências e questões com os outros, uma vez que o aprendizado é inerentemente um processo dialógico-social, como mostram vários estudiosos, entre os quais Duffy \& Cunningham (1996). Assim, por exemplo, por meio de práticas autênticas ou baseadas em casos ou em soluções de problemas, as atividades instrucionais podem se centrar na aprendizagem ativa, construtiva, intencional, autêntica e cooperativa para que resultem em um aprendizado mais significativo.

Depreende-se do estudo de Jonassen et al. (1999) que a tecnologia pode ser usada no processo de aprendizagem como ferramenta, veículo de informação, cenário, meio social e, ainda, parceira intelectual. Como ferramenta, ela permite a construção do conhecimento pela representação das idéias e, como veículo de informação, viabiliza a exploração do conhecimento, o acesso à informação e a comparação de perspectivas e pontos de vista. A tecnologia atuando como cenário permite a representação e a simulação de problemas e situações do mundo real, entre outros aspectos. Como meio social, por sua vez, a tecnologia colabora para o aprendizado por meio da possibilidade que oferece não só de colaboração com os outros, mas também de discussão, argumentação e construção de consenso. Por fim, ela atua como parceira intelectual porque pode contribuir para o aprendizado por meio da reflexão, ajudando o aprendiz a articular o que ele conhece, a refletir sobre o que aprendeu e como o fez e a construir sentidos.

Desse modo, parece-nos evidenciado por que podemos usar como suporte do ensino de línguas (online, semipresencial ou presencial) as TICs, em especial o computador: com o auxílio desses recursos amplia-se a possibilidade de propiciar aos alunos condições para que aprendam, além da língua, a interagir nas novas comunidades que se formam com o surgimento das novas tecnologias e, conseqüentemente, dos novos gêneros textuais digitais que nascem das necessidades da sociedade e como resultado das mudanças de práticas sociais.

Podemos criar oportunidades dentro e fora da sala de aula presencial para a prática e a exploração dos usos lingüísticos, quer seja de língua materna quer seja de estrangeira. É preciso, para isso, considerar a perspectiva pedagógica que prioriza incitar o aprendizado que ocorre de forma cooperativa/colaborativa, por meio da 
interação entre o aluno e o professor ou entre os alunos, estimulando a autoaprendizagem e o desenvolvimento da autonomia e reflexão.

\section{Referências}

ALMEIDA, L. K. (2005). Funcionamento dos gêneros textuais de interação em EAD. Relatório de IC. São Paulo: PUC-SP.

ALMEIDA, M. E. B. de (s/d.). Tecnologia e Educação a Distância: abordagens e contribuições dos ambientes digitais e interativos de aprendizagem. Educação $e$ Comunicação, 16. Disponível em http://www.anped.org.br/26/trabalhos/ mariaelizabethalmeida.rtf. Data de acesso: 11/11/03.

ALMEIDA, M. E. B. de; VALENTE, J. A . \& PRADO, M. E. B. (orgs). (2003). Educação a distância via Internet. Formação de educadores. São Paulo: Avercamp.

ALONSO, K. M. (s/d.). Educação a distância no Brasil: a busca de identidade. Disponível em www.nead.ufmt.br/documentos/Ident.doc. Data de acesso: 01/08/05.

ALVES, J. R. M. (s/d.). Educação a distância e as Novas Tecnologias de Informação e Aprendizagem. Disponível em

www.bibvirt.futuro.usp.br/textos/artigos/educadist.PDF. Data de acesso: 01/08/05.

BORGES, I. (2000). Prática pedagógica, processos interativos humanos e a construção do conhecimento usando a Internet: uma análise a partir da Teoria Histórico-Cultural de Lev S. Vygotsky. Dissertação de Mestrado. Florianópolis: UFSC. Disponível em http://teses.eps.ufsc.br/Resumo.asp?1233. Data de acesso: 13/12/2004.

CNE (2001). Diretrizes Curriculares para os cursos de Letras. Parecer CES 492/2001. Brasília, MEC.

CNE (2002). Diretrizes Curriculares Nacionais para a Formação de Professores da Educação Básica, em nível superior, curso de licenciatura, de graduação plena. Resolução CNE/CP 1/2002. Brasília, Diário Oficial da União, 9 de abril de 2002, seção I.

COLLINS, H. \& BRAGA, D. (2001). Interação e interatividade no ensino de línguas estrangeira via redes de comunicação. In: Globalización y nuevas tecnologías: nuevos retos y ¿nuevas reflexiones?. Madrid: Ed. Madrid/Organización de Estados Iberoamericanos para la Educación, la Ciencia y la Cultura (OEI), 2004, v.7.

COSTA, L. A. (2001). A mediação do professor na interação do aprendiz com o material didático em contextos pedagógicos distintos: o presencial e o virtual. Dissertação de Mestrado. Campinas: Unicamp.

CRESCITELLI, M. F. C. (2004). Considerações acerca de gêneros textuais utilizados para interação em EAD. In: BASTOS, N. M. O. B. Língua Portuguesa em calidoscópio. São Paulo: EDUC/FAPESP, p. 357-371.

CRESCITELLI, M. F. C. \& CAMPOS, K. S. R. (no prelo). A escrita do material didático online. In: BASTOS, N. M. O. B. Língua Portuguesa. São Paulo: EDUC/FAPESP.

CRESCITELLI, M. F. C. \& GERALDINI, A . F. S. (2004). Cursos digitais: tecnologia educacional, interação e perfil dos alunos. Revista Unicsul, 11, p. 22-32.

DUFFY \& CUNNINGHAM (1996). Constructivism: implications for the design and delivery of instruction. In: JONASSEN, D. (ed.). Handbook of Research for Educational Communications and Technology. New York: Simon \& Schuster Macmillan, pp.: 170-190.

FAUSTINI, C. H. (2001). Educação a distância: um curso de leitura em língua inglesa para informática via Internet. In: PAIVA, V. L. M. (org). Interação e aprendizagem em ambiente virtual. Belo Horizonte: FALE-UMG, p. 249-269. 
FONTANA, K. B. et alli (s/d.). A atuação do tutor na educação a distância: novas considerações. Florianópolis: Centro de Educação a Distância da Universidade do Estado de Santa Catarina. Disponível em

www.ead.ufu.br/tecead_II/anais/pdfs/klalter.pdf. Data do acesso: 10/06/03.

FREIRE, M. M. (2003). Interaction and silence in online courses. Revista da ANPOLL, 15: 161-190. São Paulo: Humanitas.

FREIRE, M. M. et al. (2004). Roteiro para avaliação de cursos online de idiomas. In: Relatos de Ensino e Aprendizagem de Línguas na Internet. Campinas: Mercado de Letras, p. 245-276.

GERALDINI, A . F. S. (2003). Docência no ambiente digital: ações e reflexão. Tese de Doutorado. São Paulo: PUC-SP.

JONASSEN, D. H. (1992). What are cognitive tools? In: KOMMERS, P. A. M.; JONASSEN, D. H. \& MAYES, J. T. (eds.). Cognitive tools for learning. Berlin: Springer-Verlag, p. 1-16.

JONASSEN, D. H. (1996). Computers in the classroom: mindtools for the critical thinking. Columbus, O.H.: Merrill/Prentice-Halla.

JONASSEN, D. H. et al. (1999). Learning with technology - a constructivist perspective. Ohio, Columbus: Prentice Hall.

KNOWLES, M. (1975). Self-directed learning. Chicago: Follett Publishing Co.

LANTOLF, J. P. (2000). Sociocultural theory and second language learning. Oxford: Oxford University Press.

LEFFA, V. J. (2003). Análise automática da resposta do aluno em ambiente virtual. Revista Brasileira de Lingüística Aplicada, v.3, no. 2: 25 - 40.

LIÓN, C. G. (1995). Mitos e realiades na tecnologia educacional. In: LITWIN, E. (org.). Tecnologia educacional. Política, histórias e propostas. Porto Alegre: Artmed.

MOORE, M. \& KEARSLEY (1996). Distance education: a systems view. New York: Wadsworth Publisher.

MORAES, M. C. (1997). O paradigma educaional emergente. Campinas: Papirus.

MORAES, M. C. (2002). Tecendo a rede, mas com que paradigma? In: MORAES, M. C. (org.). Educação a distância: fundamentos e práticas. Campinas: UNICAMP/NIED.

MORAN, J. M. (1998). Mudar a forma de ensinar e de aprender com tecnologias; transformar as aulas em pesquisa e comunicação presencial-virtual. Disponível em http://www.eca.usp.br/prof/moran/uber.htm. Data de acesso: 21/07/04.

MOTTA-ROTH, D. (2001). De receptador de informação a construtor de conhecimento: o uso de chat no ensino de inglês para formandos de Letras. In: PAIVA, V. L. M. (org.). Interação e aprendizagem em ambiente virtual. Belo Horizonte: FALEUFMG, p. 230-48.

PAIVA, V. L. O. M. (2001). Derrubando paredes e construindo comunidades de aprendizagem. In: LEFFA, V. J. (org.). O professor de linguas estrangeiras: construindo a profissão. Pelotas: Educat/UCPEL, p. 193-209.

QUEVEDO, A . G. (2005). Atividades, contradições e ciclo expansivo de aprendizagem no engajamento de aluno em um curso online. Tese de Doutorado. São Paulo: LAEL.

RAMOS, R. de C. \& FREIRE, M. M. (2001). Do presencial para o virtual: um desafio para o professor de inglês. Disponível em

http://www.abed.org/br/antiga/htdocs/paper_visem/rosinda_de_castro.htm. Data de acesso: 03/09/04.

ROMISZOWSKI, A. (2004). Panorama histórico - y personal - de la evolución de la educación a distancia. Revista Brasileña de Aprendizage Abierto y a Distancia, vol. 2/4. Disponível em: http://www.abed.org.br/publique/cgi/cgilua.exe/sys/start.htm?User ActiveTemplate $=1$ por\&infoid $=912 \& \operatorname{sid}=22$ Data de acesso: $08 / 12 / 04$. 
SABBAG, M. do C. (2002). O chat e a percepção lingüística em um curso de inglês online. Dissertação de Mestrado. São Paulo: PUC-SP.

SANTI, L. C. de (2003). A afetividade de uma professora na interação com seus alunos em um curso de inglês online. Dissertação de Mestrado. São Paulo: PUC-SP.

SHERRON, G. T. \& BOETTCHER, J. V. (1997). Distance learning: the shift to interactivity. CAUSE Professional Paper Series, no. 17.

TAVARES, K. C. A. (2001). Discutindo a formação do professor online - de listas de habilidades docentes ao desenvolvimento da reflexão crítica. Disponível em http://www.comunicar.pro.br/artigos/reflex.htm. Data de acesso: 05/09/04.

TAYLOR, J. C. (2001). Fifth Generation Distance Education. Higher Education Series. Report $\mathrm{n}^{\circ}$ 40. June. Disponível em http://www.dest.gov.au/archive/highered/hes/hes40/ hes40.pdf. Data de acesso: 21/06/05.

VALENTE, J. A . (1999). Análise dos diferentes tipos de software na educação. In:

VALENTE, J. A. (org.). O computador na sociedade do conhecimento. Campinas: UNICAMP/NIED.

VYGOSTKY , L. S. (1985). Thought and Language. Cambridge, MA: The M.I.T. Press.

WADT, M. P. S. (2002). Questões de avaliação de design de um curso de inglês online. Dissertação de Mestrado. São Paulo: LAEL/PUCSP.

Abstract: After a brief chronological view on distance education, we reflect about the use of technological resources in Portuguese and foreign language teaching (in distant, blended or face-to-face courses) and show why we consider the digital technologies, specially the computer, important tools to the development of the learning processes.

Key words: distance education, language learning, Internet, digital technological resources. 